\title{
ULTRAVIOLET RADIATION IN MANUAL ARC WELDING USING COVERED ELECTRODES
}

\author{
O.G. LEVCHENKO ${ }^{1}$, A.T. MALAKHOV ${ }^{1}$ and A.Yu. ARLAMOV ${ }^{2}$ \\ ${ }^{1}$ E.O. Paton Electric Welding Institute, NASU \\ 11 Bozhenko Str., 03680, Kiev, Ukraine. E-mail: office@paton.kiev.ua \\ ${ }^{2}$ NTTU «Kiev Polytechnic Institute» \\ 37 Pobedy Ave., 03056, Kiev, Ukraine
}

\begin{abstract}
Welding arc is the source of intensive flow of optic radiation in infrared, visible and ultraviolet (UV) ranges, among which the most severe UV-C radiation with a strong harmful effect on the human organs of vision and skin covering should be distinguished. The aim of this work consisted in complex investigation of integral characteristics of UV radiation covered-electrode in manual arc welding (MAW), with covered electrodes of different grades (MR-3, UONI-13/55, ANO-12, ANO-36) and types of coatings (rutile, basic, rutile-cellulose), designed for welding of carbon and low-alloyed steels. The intensity of UV-C and UV-A radiation was measured using dosimeter of optic radiation DAU-81 at the distances of $0.55-1.50 \mathrm{~m}$ from the spot of welding. It was established during analysis and statistic processing of measurement results that at this distance at, which usually welder and support personnel are staying during MAW, the integral intensity of UV-C radiation amounts to $0.7-5 \mathrm{~W} / \mathrm{m}^{2}$, which $700-5000$ times exceeds the standard value of $0.001 \mathrm{~W} / \mathrm{m}^{2}$ specified by the acting sanitary standards SN 4557-88 for workers with non-protected skin surfaces. Here the minimum distance, at which staying of the mentioned category of workers at direct visibility of welding place is admissible, amounts from 25 to $65 \mathrm{~m}$ (depending on the grade of electrode and value of welding current). Intensity of UV-C radiation depends, in the first turn, on the grade of applied electrodes but not on the type of their coating. It was shown that the intensity of UV radiation is inversely proportional to the square of distance from welding arc and greatly depends on welding current. The results of this work can be used in sanitary-hygienic certification of working stations of welders. 6 Ref., 4 Tables.
\end{abstract}

Keywords: ultraviolet radiation, integral characteristics, safe distance, manual arc welding, covered electrodes

Welding arc is the source of not only the intensive light flow in visible range and infrared radiation, but also of invisible ultraviolet radiation (UVR) at the wave length of $200-400 \mathrm{~nm}$. According to the wave length UVR is subdivided into three ranges: UV-A (315-400 nm), UV-B (280$315 \mathrm{~nm})$ and UV-C (200-280 nm). The most severe is $\mathrm{UV}-\mathrm{C}$ radiation possessing an intensive harmful effect on the human organs of vision and skin covering. It should be noted that UV-C rays are almost absent in the spectrum of solar radiation at the earth surface, being intensively absorbed mainly in the upper ozone layer of atmosphere.

In spite of the importance of investigations of UVR in welding to provide safety of the personnel, the publications on this subject in the CIS countries are almost absent. The publications in the countries of the EU, the USA and Japan are of a specific nature characterized by a sanitaryhygiene orientation in evaluation of radiation in welding in compliance with the national stand-

(c) O.G. LEVCHENKO, A.T. MALAKHOV and A.Yu. ARLAMOV, 2014 ards different from those valid in Ukraine and the CIS countries.

Therefore, the aim of this work consisted in the complex investigation of integral characteristics of UVR in manual arc welding (MAW) using covered electrodes of different grades and types of coatings designed for welding of carbon and low-alloyed steels.

Methods of investigations. The investigations were carried out in MAW with electrodes of $4 \mathrm{~mm}$ diameter in flat position of a weld, indoor at the air temperature of $15-20{ }^{\circ} \mathrm{C}$ and average relative humidity of the air with exhaust ventilation over the place of welding. The welding source was welding rectifier VDU-506. Welding current was fixed at the values of 150, 175 and $200 \mathrm{~A}$, corresponding to the range of recommended modes for electrodes ANO-4, ANO-12, ANO-36, MR-3, UONI-13/55. The sensor of UV-C and UV-A radiation of a single-channel automatic dosimeter of optic radiation (DAU-81) was located at the fixed distances of 0.55 (outstretched arm distance), 1.0 and $1.5 \mathrm{~m}$ from welding spot in the direction under the angle of $27-30^{\circ}$ to the horizontal welding surface. The sensors were directed to the spot of welding arc under 
the conditions of its direct visibility. The value of radiation dose $\left(\mathrm{J} / \mathrm{m}^{2}\right)$ was fixed within 30$60 \mathrm{~s}$. The value of average intensity of radiation $E\left(\mathrm{~W} / \mathrm{m}^{2}\right)$ was obtained by dividing the dose to the time of measurement. For monitoring this value was checked up with the values of arrow measurer of radiation intensity of the dosimeter DAU-81. To improve the reliability of results of experiments the measurements were repeated 2-3 times under the same conditions.

Investigations results. Processing of measurement data was carried out on PC using method of the least squares. It was established in the course of measurements that the intensity of radiation depends greatly on the distance $d(\mathrm{~m})$ to the radiation source (welding arc) and on welding current $I$ (A). Preliminary the hypothesis was offered that at the given distances the intensity of radiation is governed by the law of inverse squares $\left(E \sim 1 / d^{2}\right)$. During processing of results of measurements this dependence was proved with a high accuracy. It should be noted that the same dependence was obtained in the work in $\mathrm{CO}_{2}$ welding [1]. From the physical point of view, this corresponds to the conditions of free spreading of optic radiation from the spot source and means that the welding arc at the investigated interval of distances $(0.55-1.50 \mathrm{~m})$ can be considered as a spot source, from which the processes of absorption, diffusion dissipation and reflection of light flow do not considerably influ- ence the spreading of radiation flow. This phenomenon is quite expected under the given conditions of welding and measurements. Then we shall write the dependence $E(d, I)$ as

$$
E=\frac{a+b I}{d^{2}} .
$$

The coefficients $a$ and $b$ were calculated using method of the least squares in the matrix form [2]. Such approach allowed including the results of measurements at different distances to the processing, which increased the validity of calculated coefficients due to growth in number of measurement spots. The obtained values of the coefficients are given in Table 1 . The values of correlation coefficients $R^{2}$ in the Table indicate a quite high accuracy of relation between the factorial (current strength) and resulting (radiation intensity) characteristics.

Let us note that the similar (1) dependence of efficient intensity of radiation on welding current at a fixed distance from the place of welding was obtained in work [3]. The wider range of changes in welding current (45-250 A) was obtained by integration of measurements results in MAW using electrodes of different diameter.

For comparative evaluation of influence of electrode grade and coating on the intensity of radiation, Table 2 was compiled, where values of radiation intensity, calculated according to

Table 1. Coefficients of dependence (1) obtained as a result of processing of measurement data

\begin{tabular}{||c|c|c|c|c|c|c|c|}
\hline \multirow{2}{*}{ Grade of electrode } & \multirow{2}{*}{ Type of coating } & \multicolumn{3}{|c|}{ UV-C } & \multicolumn{3}{|c|}{ UV-A } \\
\cline { 3 - 8 } & & $a, \mathrm{~W}$ & $b, \mathrm{~W} / \mathrm{A}$ & $R^{2}$ & $a, \mathrm{~W}$ & $b, \mathrm{~W} / \mathrm{A}$ & $R^{2}$ \\
\hline UONI-13/55 & Basic & -7.7275 & 0.0562 & 0.9736 & -5.4838 & 0.0439 & 0.9645 \\
\hline ANO-12 & Same & -10.14 & 0.0719 & 0.9901 & -7.4335 & 0.0530 & 0.9562 \\
\hline MR-4 & Rutile & -6.0125 & 0.0459 & 0.9942 & -9.1275 & 0.0682 & 0.9310 \\
\hline MR-3 & Same & -8.485 & 0.0629 & 0.9683 & -9.4144 & 0.0706 & 0.9322 \\
\hline ANO-36 & Rutile-cellulose & -8.8575 & 0.0627 & 0.9686 & -9.5375 & 0.0730 & 0.9627 \\
\hline
\end{tabular}

Note. $R^{2}-$ statistic correlation coefficient.

Table 2. Calculated values of UVR intensity $(d=1 \mathrm{~m})$

\begin{tabular}{|c|c|c|c|c|c|c|c|}
\hline \multirow{3}{*}{ Grade of electrode } & \multirow{3}{*}{ Type of coating } & \multicolumn{3}{|c|}{$\mathrm{UV}-\mathrm{C}, \mathrm{W} / \mathrm{m}^{2}$} & \multicolumn{3}{|c|}{$\mathrm{UV}-\mathrm{A}, \mathrm{W} / \mathrm{m}^{2}$} \\
\hline & & \multicolumn{3}{|c|}{$I, \mathrm{~A}$} & \multicolumn{3}{|c|}{$I, \mathrm{~A}$} \\
\hline & & 150 & 175 & 200 & 150 & 175 & 200 \\
\hline ANO-4 & Rutile & 0.87 & 2.0 & 3.2 & 1.1 & 2.8 & 4.5 \\
\hline UONI-13/55 & Basic & 0.70 & 2.1 & 3.5 & 1.1 & 2.2 & 3.3 \\
\hline ANO-36 & Rutile-cellulose & 0.55 & 2.1 & 3.7 & 1.4 & 3.2 & 5.1 \\
\hline ANO-12 & Basic & 0.65 & 2.4 & 4.2 & 0.5 & 1.8 & 3.2 \\
\hline MR-3 & Rutile & 0.95 & 2.5 & 4.1 & 1.2 & 2.9 & 4.7 \\
\hline
\end{tabular}


formula (1) at different values of current at the distance of $1 \mathrm{~m}$, are given.

In this Table the values of intensities of UV-C radiation are ranged in the growing order at the average value of welding current of $175 \mathrm{~A}$. As is seen, approximately the same ranging is preserved also for 200 A current. At the lower boundary of the investigated range at the current of 150 A the ranging is considerably different. Obviously, it is connected with instability of arcing process at these modes of welding using electrodes of $4 \mathrm{~mm}$ diameter.

The analysis of Table 2 shows that emission of UV-C radiation in welding is determined by the grade of electrode but not by the type of its coating. The emission of UV-C rays in even greater extent depends on the strength of welding current. The significant current dependence allows assuming that intensity of optic radiation mainly depends on power generating in the zone of welding arc, and in the less extent on spectral peculiarities of radiation predetermined by the grade and type of electrode coating.

In compliance with the sanitary standards $\mathrm{SN}$ 4557-88 [4] in the industrial facilities the following admissible UVR intensities were established:

- admissible intensity of radiation of personnel at the presence of non-protected areas of skin surface of not more than $0.2 \mathrm{~m}^{2}$ and radiation period of up to $5 \mathrm{~min}$, at duration of pauses between them of not less than $30 \mathrm{~min}$ and total duration of effect per shift of up to $60 \mathrm{~min}$, should not exceed, $\mathrm{W} / \mathrm{m}^{2}: 50$ for UV-A, 0.05 for UV-B, and 0.001 for $\mathrm{UF}-\mathrm{C}$ radiation;

- admissible intensity of UVR of personnel with unprotected areas of skin surface is not more than $0.2 \mathrm{~m}^{2}$ (face, neck, hands, etc.) at total duration of effect of radiation of $50 \%$ of working shift and duration of one-time radiation of more than $5 \mathrm{~min}$ and more, should not exceed, $\mathrm{W} / \mathrm{m}^{2}$. 10 for UV-A and 0.01 for UV-B rays; radiation in the $\mathrm{UV}-\mathrm{C}$ range at the mentioned duration is not admitted.

Considering these standards, let us define the safe distances $d_{\text {s }}$ for workers with non-protected areas of skin surface, staying in the direction of direct visibility of welding place. Let us assume free spreading of UV rays with inverse-proportional dependence of intensity on square of distance $E \sim 1 / d^{2}$. In this case the $d_{s}$ value can be calculated according to formula

$$
d_{\mathrm{S}}=\sqrt{\frac{a+b I}{E_{\mathrm{S}}}}(\mathrm{m}),
$$

where $a, b$ are the coefficients, the values of which are given in Table $1 ; E_{\mathrm{s}}$ is the boundary admissible value of radiation intensity corresponding to the safety standards.

In Table 3 the calculated values of $d_{\mathrm{s}}$ at $E_{\mathrm{s}}=$ $=0.001 \mathrm{~W} / \mathrm{m}^{2}$ for UV-C and $E_{\mathrm{s}}=50 \mathrm{~W} / \mathrm{m}^{2}$ for $\mathrm{UV}$-A range are given.

As we see, minimum distances, at which the support personnel in MAW can stay in the direction of direct visibility of welding place, are very long in case of effect of UV-C rays. For UV-A radiation these distances are considerably smaller, therefore, the spectrum area determining the safety is the UV-C radiation. In case of necessity of staying of support personnel in a quite wide area of dangerous effect it is necessary to take measures for protection of skin covering and eyes from the mentioned radiation.

In Table 3 the safe distances are given for temporary characteristics of effect according to sanitary standards SN 4557-88 valid in Ukraine. In particular, during the working shift the summed time of effect of UV-C radiation should not exceed $60 \mathrm{~min}$. In the EU countries the conditions of safety are determined by Directive $2006 / 25 / \mathrm{EC}$ [5]. In particular, the limited efficient dose of UVR effect during the working shift $(8 \mathrm{~h})$ is restricted by the value $H_{\mathrm{es}}=$ $=30 \mathrm{~J} / \mathrm{m}^{2}$. Knowing the value of intensity of $\mathrm{UV}-\mathrm{C}$ radiation under the specified conditions the admissible time of effect $t_{\mathrm{s}}$ can be calculated by dividing $H_{\mathrm{es}} / E$. In Table 4 the calculated values of safe distances at the certain time of effect of UV-C radiation are given. For the preset time of effect $t_{\mathrm{s}}$ the admissible value $E_{\mathrm{s}}=H_{\mathrm{es}} / t_{\mathrm{s}}$ was found, and then the $d_{\mathrm{s}}$ value was calculated according to formula (2).

It should be noted that calculated values of safe distances obtained using the analogue method [6], are not considerably differ from the values given in Table 4.

Comparison of values in Tables 3 and 4 show that at the same intensity of radiation the sanitary

Table 3. Calculated values of safe distances $\left(d_{\mathrm{s}}, \mathrm{m}\right)$ at the UVR effect on support personnel in MAW

\begin{tabular}{||c|c|c|c|c|c|c||}
\hline \multirow{2}{*}{$\begin{array}{c}\text { Grade of } \\
\text { electrode }\end{array}$} & \multicolumn{3}{|c|}{ UV-C } & \multicolumn{3}{c||}{ UV-A } \\
\cline { 2 - 7 } & 150 & 175 & 200 & 150 & 175 & 200 \\
\cline { 2 - 7 } & 30 & 45 & 57 & 0.15 & 0.24 & 0.30 \\
\hline ANO-4 & 27 & 46 & 60 & 0.15 & 0.21 & 0.26 \\
\hline UONI-13/55 & 24 & 46 & 61 & 0.17 & 0.25 & 0.32 \\
\hline ANO-36 & 26 & 49 & 65 & 0.10 & 0.19 & 0.25 \\
\hline ANO-12 & 31 & 50 & 64 & 0.16 & 0.24 & 0.31 \\
\hline MR-3 & & & & & & \\
\hline
\end{tabular}


Table 4. Calculated values of safe distances $\left(d_{\mathrm{s}}, \mathrm{m}\right)$ at the UV-C radiation effect on support personnel in MAW depending on time of effect $(I=200 \mathrm{~A})$

\begin{tabular}{|c|c|c|c|c|c|c|c|}
\hline \multirow{4}{*}{ Grade of electrode } & \multicolumn{7}{|c|}{$t_{\mathrm{s}}, \min$} \\
\hline & 1 & 10 & 30 & 60 & 120 & 240 & 480 \\
\hline & \multicolumn{7}{|c|}{$E_{\mathrm{s}}, \mathrm{W} / \mathrm{m}^{2}$} \\
\hline & 0.5 & 0.05 & 0.017 & 0.008 & 0.004 & 0.002 & 0.001 \\
\hline ANO-4 & 2.6 & 8.2 & 14 & 20 & 29 & 40 & 57 \\
\hline UONI-13/55 & 2.7 & 8.7 & 15 & 21 & 30 & 42 & 60 \\
\hline ANO-36 & 2.8 & 8.8 & 15 & 22 & 31 & 43 & 61 \\
\hline ANO-12 & 3.0 & 9.4 & 16 & 23 & 33 & 46 & 65 \\
\hline MR-3 & 2.9 & 9.2 & 16 & 23 & 32 & 45 & 64 \\
\hline
\end{tabular}

standards SN 4557-88, unlike the EU standards specify the more severe restrictions for the admissible time of effect. Besides, the EU standards admit the effect of UV-C radiation with intensity of more than $0.001 \mathrm{~W} / \mathrm{m}^{2}$, which is prohibited by $\mathrm{SN} 4557-88$. In this sense the EU standards are developed in the greater details, flexible and grounded from the physical point of view.

\section{Conclusions}

1. It was established that at the distances from 0.5 to $1.5 \mathrm{~m}$, at which welder and support personnel are usually staying in MAW using covered electrodes, the integral intensity of UV-C radiation amounts from 0.7 to $5 \mathrm{~W} / \mathrm{m}^{2}$, which $700-$ 5000 times exceeds the standard value of $0.001 \mathrm{~W} / \mathrm{m}^{2}$ specified by the efficient sanitary standards SN 4557-88 for working personnel with non-protected areas of skin surface. Here, the minimum distances, at which staying of the mentioned category of workers at direct visibility of welding place is admissible, amounts from 25 to $65 \mathrm{~m}$ (depending on grade of electrode and strength of welding current).
2. It was established that the intensity of UV-C radiation depends, in the first turn, on the grade of applied electrodes but not on the type of their coating (rutile, basic, rutile-cellulose). It was shown that intensity of UVR is inversely proportional to the distance from welding arc.

1. Okuno, T, Ojima, J., Saito, H. (2001) Ultraviolet radiation emitted by $\mathrm{CO}_{2}$ arc welding. Annals Occup. Hygience, 45(7), 597-601.

2. Magnus, Ya.R., Katyshev, P.K., Peresetsky, A.A. (1998) Econometrics: Basic training. Moscow: Delo.

3. Schwass, D., Witllich, M., Shmitz, M. et al. (2011) Emission of UV radiation during arc welding. wकw. dguv.de ifa. 1-12

4. $S N$ 4557-88: Sanitary norms of ultraviolet radiation in production premises. Introd. 23.02.1988. Moscow: Minzdrav SSSR.

5. Directive 2006/25/EC of the European Parliament and of the Council of 5 April 2006 on the minimum health and safety requirements regarding the exposure on workers to risks arising from physical agents (artificial optical radiation).

6. Terry, L. Lyon. (2002) Knowing the dangers of actinic ultraviolet emissions. Welding J., Dec., 28-30.

Received 09.04.2014 